\title{
Avoidance behaviour performed in the context of a novel, ambiguous movement increases threat and pain-related fear
}

Citation for published version (APA):

van Vliet, C. M., Meulders, A., Vancleef, L. M. G., \& Vlaeyen, J. W. S. (2021). Avoidance behaviour performed in the context of a novel, ambiguous movement increases threat and pain-related fear. Pain, 162(3), 875-885. https://doi.org/10.1097/j.pain.0000000000002079

Document status and date:

Published: 01/03/2021

DOI:

10.1097/j.pain.0000000000002079

Document Version:

Publisher's PDF, also known as Version of record

Document license:

Taverne

Please check the document version of this publication:

- A submitted manuscript is the version of the article upon submission and before peer-review. There can be important differences between the submitted version and the official published version of record.

People interested in the research are advised to contact the author for the final version of the publication, or visit the DOI to the publisher's website.

- The final author version and the galley proof are versions of the publication after peer review.

- The final published version features the final layout of the paper including the volume, issue and page numbers.

Link to publication

\footnotetext{
General rights rights.

- You may freely distribute the URL identifying the publication in the public portal. please follow below link for the End User Agreement:

www.umlib.nl/taverne-license

Take down policy

If you believe that this document breaches copyright please contact us at:

repository@maastrichtuniversity.nl

providing details and we will investigate your claim.
}

Copyright and moral rights for the publications made accessible in the public portal are retained by the authors and/or other copyright owners and it is a condition of accessing publications that users recognise and abide by the legal requirements associated with these

- Users may download and print one copy of any publication from the public portal for the purpose of private study or research.

- You may not further distribute the material or use it for any profit-making activity or commercial gain

If the publication is distributed under the terms of Article $25 \mathrm{fa}$ of the Dutch Copyright Act, indicated by the "Taverne" license above, 


\title{
Avoidance behaviour performed in the context of a novel, ambiguous movement increases threat and pain-related fear
}

\author{
Christine M. van Vliet ${ }^{a, b, *}$, Ann Meulders ${ }^{a, b}$, Linda M.G. Vancleef ${ }^{b}$, Johan W.S. Vlaeyen ${ }^{a, b}$
}

\begin{abstract}
The fear-avoidance model of chronic pain predicts that catastrophic (mis)interpretation of pain elicits pain-related fear that in turn may spur avoidance behaviour leading to chronic pain disability. Here, we investigated whether performing a movement to avoid a painful stimulus in the context of a novel movement increases threat and pain-related fear towards this novel movement and whether avoidance behaviour persisted when given the choice between performing the acquired movement to avoid a painful stimulus or an alternative, novel movement. Applying a robotic arm-reaching task, participants could choose between 2 movements to reach a target location: a short, but painful movement trajectory, or a longer nonpainful movement trajectory. After avoidance acquisition, the option to choose the painful trajectory was removed. The experimental group $(N=50)$ could choose between the longest trajectory or a novel intermediate trajectory, whereas the control group $(N=50)$ was allowed to only perform the novel trajectory. In a final test, participants of both groups were allowed to choose any of the 3 trajectories. After acquisition, experimental group participants showed elevated pain expectancy and pain-related fear towards the novel trajectory, compared with the control group. During test, the experimental group participants persisted in performing the longest pain-free (avoidance) trajectory and were less likely to choose the novel trajectory. In addition, these participants maintained higher levels of pain-related fear for the novel trajectory compared with the control group. These findings suggest that avoidance in the context of other neutral activities/movements may lead to the development and maintenance of threat appraisals and irrational fears.
\end{abstract}

Keywords: Avoidance, Threat, Pain-related fear, Pain

\section{Introduction}

According to fear-avoidance models, pain-related fear and avoidance behaviour have been proposed to account for the transition of a common acute pain episode to chronic disabling pain. ${ }^{15,19,34,35}$ Individuals avoiding aversive events may misattribute the perceived safety to the just emitted avoidance response, and therefore, they cannot challenge the veracity of the threat that led to the avoidance response. ${ }^{17,26}$ In a pain-related fear-conditioning experiment, Volders et al. ${ }^{37}$ demonstrated that performing an avoidance response during a painful movement and the subsequent removal of the avoidance response hampered the extinction of fear of movement-related pain. Studies by van Vliet et al., 31,32 investigating the bidirectional relationship between avoidance behaviour and pain-related fear,

Sponsorships or competing interests that may be relevant to content are disclosed at the end of this article.

a Research Group Health Psychology, Faculty of Psychology and Educational Sciences, KU Leuven, Leuven, Belgium, ${ }^{b}$ Experimental Health Psychology, Faculty of Psychology and Neuroscience, Maastricht University, Maastricht, the Netherlands

*Corresponding author. Address: Faculty of Psychology and Educational Sciences, Research Group Health Psychology, KU Leuven, Tiensestraat 102, box 3726, 3000 Leuven, Belgium. Tel.: +32 (0)16 3742 49. E-mail address: christine.vanvliet@ kuleuven.be (C. van Vliet).

Supplemental digital content is available for this article. Direct URL citations appear in the printed text and are provided in the HTML and PDF versions of this article on the journal's Web site (www.painjournalonline.com).

PAIN 162 (2021) 875-885

(C) 2020 International Association for the Study of Pain

http://dx.doi.org/10.1097/j.pain.0000000000002079 revealed that avoidance behaviour is not only the result of pain-related fear but also that avoidance behaviour in itself may increase fear. Several explanations can be given how a history of avoidance behaviour leads to fear responding. First, avoidance behaviour may be used as a source of information of the potential threat. ${ }^{10,28}$ Therefore, avoiding more frequently could elevate pain expectancies and pain-related fear. Second, avoiding safe stimuli may induce cognitive dissonance. Since the emitted behaviour is not in line with the actual threat, individuals may resolve this dissonance by adjusting their threat attribution to fit their behaviour. ${ }^{8,30}$ Third, the mere availability of avoiding stimuli with an ambiguous outcome may cause increased threat expectancies. ${ }^{20,30}$ The avoidance response itself may induce transfer of threat and pain-related fear towards the ambiguous stimulus. Finally, the availability of an acquired avoidance response may function as a contextual cue indicating the presence of a potential threat. $^{7,33}$

Does emitting avoidance behaviour in an obvious situation influence the threat value of a novel and ambiguous stimulus that is brought into the same context? To investigate this question, we examined whether (1) acquired avoidance behaviour in the context of a novel ambiguous movement provoked pain expectancy and pain-related fear towards that movement and (2) whether avoidance behaviour persisted when given the choice to perform either the acquired avoidance behaviour or a novel movement.

In a robotic arm-reaching task, participants learned that the shortest movement trajectory ( $\mathrm{T} 1$ ) was followed by a painful stimulus, which they could avoid by choosing a longer trajectory (T3). Next, we removed the option to perform T1 and introduced a 
novel, intermediate trajectory (T2). Performance of T2 was paired with pain only the first time a participant chose this movement trajectory. The experimental group was given the free choice to perform either the avoidance behaviour (T3) or the novel trajectory (T2). The control group was allowed to only perform T2. At test, all participants were given the opportunity to freely choose any of the 3 trajectories (T1, T2, and T3). We hypothesized (1) that acquired avoidance behaviour in the presence of a novel movement (T2) would provoke pain expectancy and pain-related fear towards that movement; (2) that pain expectancy and pain-related fear as well as (3) avoidance behaviour would persist during a free-choice test; and (4) that more frequent avoiders would report higher pain expectancy and pain-related fear than less frequent avoiders.

\section{Methods}

\subsection{Participants}

A total of 100 healthy, pain-free volunteers participated in this study ( 80 women; mean \pm SD age $=22 \pm 8$ years). Participants were recruited at $\mathrm{KU}$ Leuven, using social media and distribution of flyers around the campus. Psychology students received half a course credit for participation or a monetary compensation of $€ 4$. All participants provided written informed consent, which stated they were allowed to decline participation at any time during the experiment without any consequences. Participants were excluded if they reported to suffer from any cardiovascular disease, chronic pain conditions, pain in the right forearm, impaired uncorrected vision, medical advice to avoid stressful situations, psychiatric disorders (current or in the past), neurological conditions, or were pregnant. Participants were assigned to the experimental group ( $n=50,41$ women) or the control group $(n=$ 50,39 women) through block randomisation. The Social and Societal Ethics Committee of KU Leuven approved the experimental protocol (Reg \#: G-2018 11 1397).

\subsection{Apparatus and stimulus material}

\subsubsection{HapticMaster}

The HapticMaster $(H M)$ is a 3 degrees of freedom, forcecontrolled robotic arm (Moog, Inc, FCS Robotics, East Aurora, New York) and allows for a wide range of movements (Fig. 1). In the current study, movements were restricted to the horizontal plane with depth of $0.35 \mathrm{~m}$ and $\mathrm{a} 1-\mathrm{m}$ radius. ${ }^{20}$ The position of the $\mathrm{HM}$ was consistently logged through a computer, such that the coordinates could be used as input for the painful stimulus presentation.

\subsubsection{Stimulus material}

An electrocutaneous stimulus of 2 milliseconds' duration served as the painful stimulus. The stimulus was delivered by a commercial stimulator (DS7A, Digitimer, Welwyn Garden City, England), using bar electrodes filled with $\mathrm{K}-\mathrm{Y}$ gel that were attached to the triceps tendon of the right arm, which was used to perform the movements through the reaching task with the robotic arm. Note that a calibration procedure was performed to select a stimulus intensity that was painful and took some effort to tolerate (see calibration phase).

\subsubsection{Hardware and software}

The experiment was run on a Windows 7 Professional (Microsoft Corporation Redmond, WA) 64-bit Dell Latitude 6420 computer

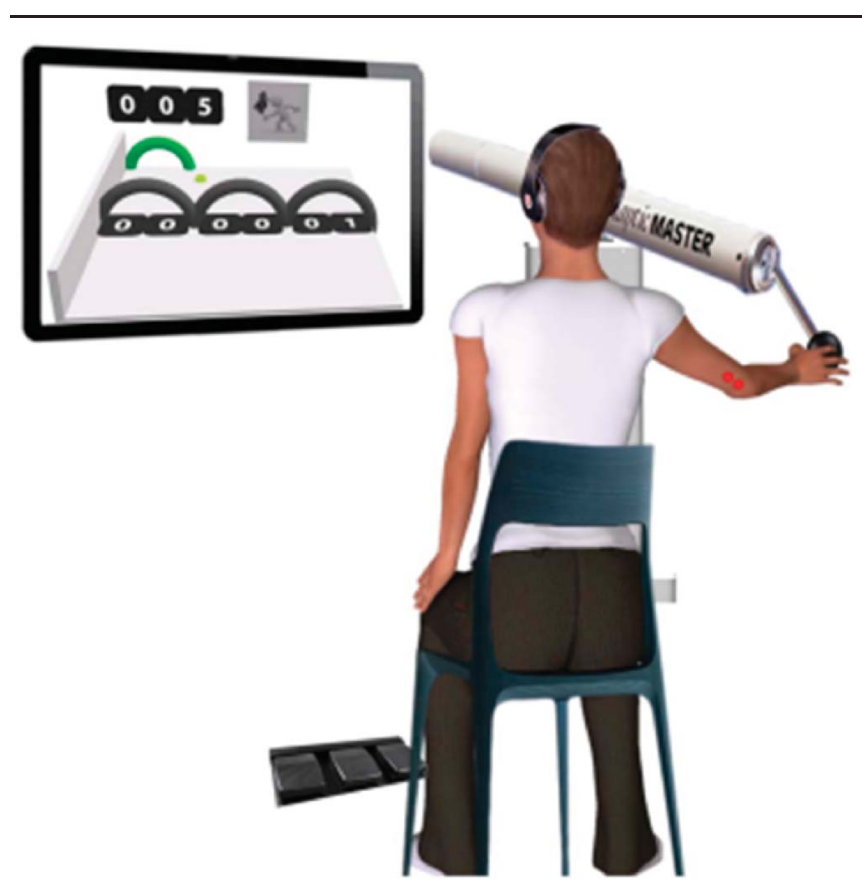

Figure 1. Experimental set-up showing the position of the participant in front of the screen, using the HapticMaster for the arm-reaching task. ${ }^{20}$

(Dell, Inc, Round Rock, TX) with 4 GB RAM, CPU: 15-2520M at 2.5 $\mathrm{GHz}$ and programmed in $\mathrm{C} / \mathrm{C}++$. All data recording and processing was performed using a commercial software package (MATLAB version; The MathWorks, Inc, Natick, MA, 2000).

\subsection{Study protocol}

The experiment was conducted during a single 30-minute session and consisted of the following phases: preparation, calibration, practice, avoidance acquisition, avoidance manipulation (AM), and free-choice test. We used a between-subject design including an experimental $(N=50)$ and control group $(N=$ 50). After the experiment, participants completed trait questionnaires (Dutch versions) to assess fear of pain (FPQ-III-NL ${ }^{18,25}$ ), trait anxiety, ${ }^{29}$ intolerance of uncertainty, ${ }^{12}$ and neuroticism. ${ }^{9}$

\subsubsection{Robotic arm-reaching task}

Participants performed reaching movements with their right arm using the HM. The task consisted of bringing a "green ball" from the starting point (left lower corner of the movement plane) to the target location (left top corner of the movement plane; see Fig. 2). The ball represented real-time movement, and the movement plane was represented on a screen. Participants could freely choose several movement trajectories to reach the target location, and these were indicated by arches positioned in the middle of the movement plane. The trajectories differed in deviation towards the target location. No specific instructions were given to the participants regarding the movements, so they could freely discover which movements led to which outcomes.

\subsubsection{Preparation and calibration phase}

Participants received oral and written information about the experiment and were told they could decline participation of the experiment at any time without any consequences. After signing the informed consent, stimulation electrodes were attached to the right arm above the elbow and the calibration phase began. During the 


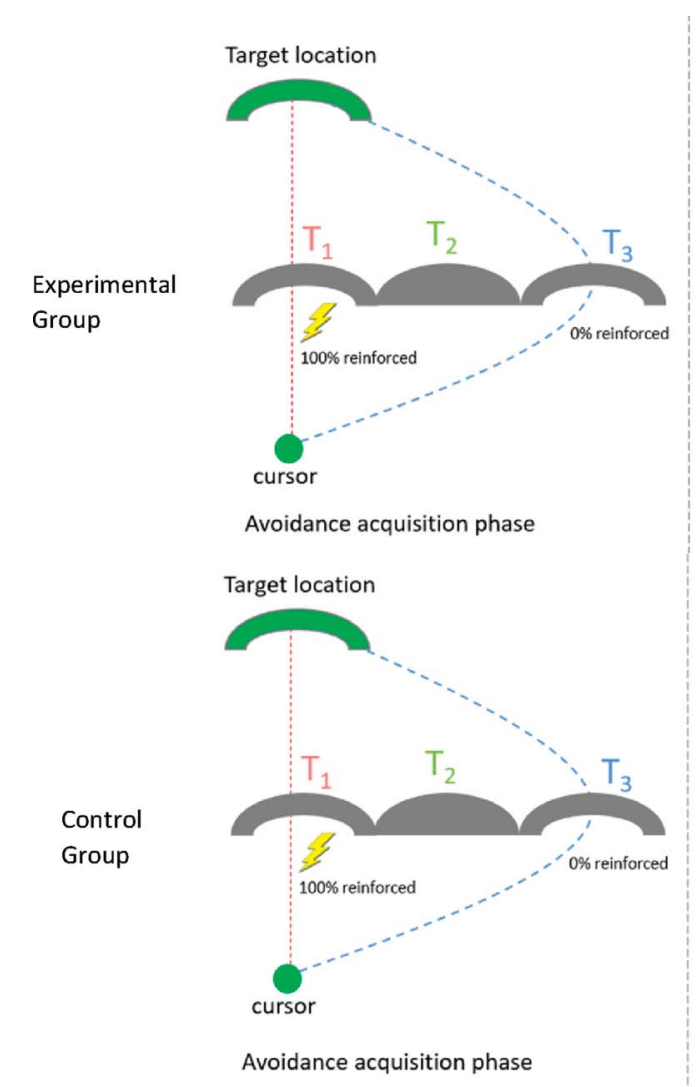

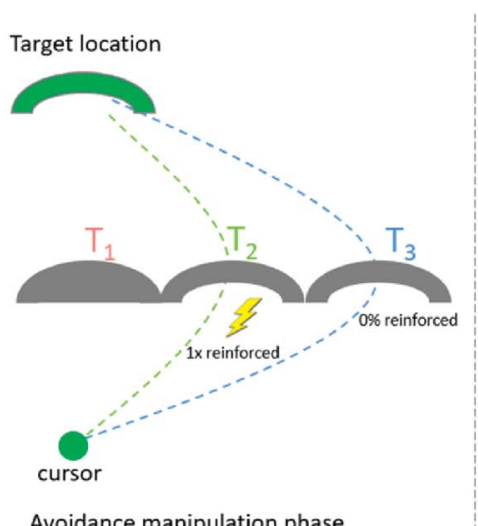

Avoidance manipulation phase

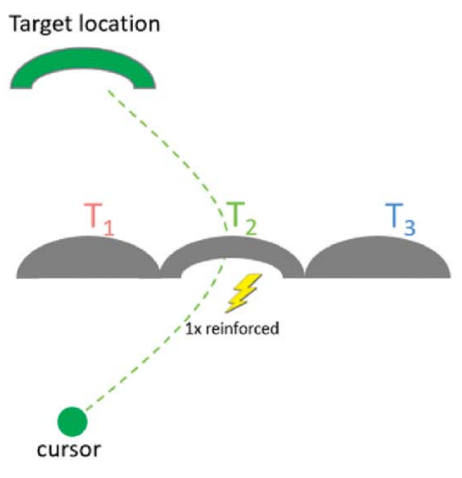

Avoidance manipulation phase

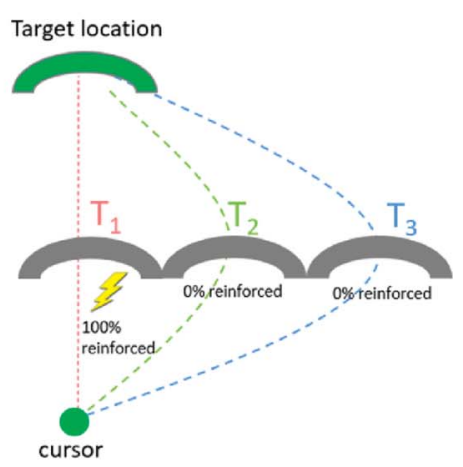

Free-choice test phase

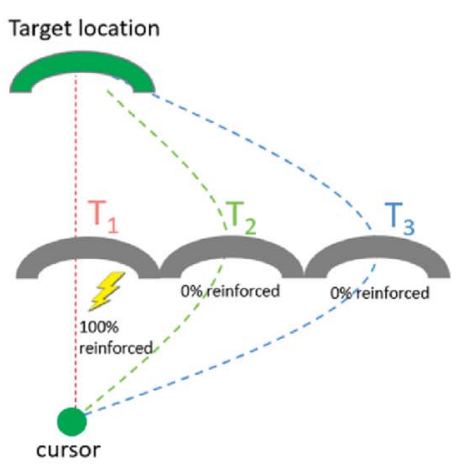

Free-choice test phase

Figure 2. Experimental design.

calibration procedure of the painful stimuli, participants were repeatedly exposed to electrical stimulation of gradually increasing intensity, starting at $2 \mathrm{~mA}$, increasing in increments of $2 \mathrm{~mA}$ up to an intensity of $8 \mathrm{~mA}$ and then continued in increments of $3 \mathrm{~mA}$ up to an intensity of $20 \mathrm{~mA}$, and then continued in increments of $4 \mathrm{~mA}$ up to an intensity of $52 \mathrm{~mA}$. Beyond $52 \mathrm{~mA}$, increments were reduced to $2 \mathrm{~mA}$ again. Participants selected a stimulus that was painful and demanded some effort to tolerate. Participants were informed that if they did not wish to receive a painful stimulus of a higher intensity, or if they wanted the amplitude to be set back to a lower intensity, they could notify the experimenter who then adjusted the stimulus accordingly. This stimulus intensity was used as the painful stimulus throughout the experiment and was not adjusted anymore after the calibration phase. After calibration, participants read more specific written instructions on the TV screen.

\subsubsection{Practice phase}

During this phase (12 trials), participants were familiarized with the different movement trajectories (T1, T2, and T3). Participants performed 1 of the 3 movements when a start signal was given (= brief sound simultaneously with on-screen presentation of a manikin raising a flag on the upper right corner of the screen), and participants also practiced the use of the foot switch (USB-3FS-2; Scythe, Tokyo, Japan) to provide ratings. A foot switch was used instead of a manual switch to avoid interference with the armreaching movements in this experiment. When participants reached the target location, a brief sound together with an on-screen red stop-signal was presented, which indicated that the trial ended. The $\mathrm{HM}$ robotic arm then returned to its initial starting position, where it remained fixed until the start of the next trial (intertrial interval $=3$ seconds). No painful stimuli were delivered during this phase.

\subsubsection{Avoidance acquisition phase}

Instructions remained the same as during practice, except that movement trajectory T2 was not available anymore, giving the participants the choice between trajectories T1 or T3. During this phase, T1 was always paired with a painful electrocutaneous stimulus, whereas T3 was not. The painful stimulus was delivered exactly at the point in time when the participant passed the green ball through the arch of T1. In total, 24 trials were run, during which participants acquired pain-related fear for movement T1, but not for movement T3, and could learn to avoid the painful stimulus by performing the longer trajectory movement (T3), ie, acquisition of the avoidance behavior.

\subsubsection{Avoidance manipulation phase}

After the avoidance acquisition phase, the option to perform the shortest trajectory $\mathrm{T} 1 \mathrm{w}$ was removed and the intermediate movement trajectory T2 now became available for both groups (12 trials). Performance of T2 was paired with pain only the first time a participant chose this movement trajectory. From the second T2 movement onwards, no painful stimuli were given anymore, but this information was unknown to the participants. The experimental group participants could freely choose to move either through T2 or T3, whereas the control group was only allowed to perform the novel trajectory T2. The single-trial reinforcement of T2 was applied because earlier pilot testing had shown that in the absence of this single-trial reinforcement, participants did not avoid anymore (ie, choose T3) which was crucial for our manipulation.

\subsubsection{Free-choice test phase}

In the final test, all trajectories were made available for both groups. Again, participants performed 12 trials in which they 
could freely choose which movements they performed. Only movement trajectory $\mathrm{T} 1$ was always paired with a painful electrocutaneous stimulus, while T2 and T3 were never paired with a painful electrocutaneous stimulus in this phase.

\subsection{Outcome measures}

\subsubsection{Behavioural avoidance: movement choice}

On each movement trial, movement choices were recorded ( $\mathrm{T} 1$, T2, and T3). We calculated the proportion of each selected trajectory per group and phase.

\subsubsection{Pain expectancy and pain-related fear ratings}

\subsubsection{Retrospective ratings}

Retrospective ratings were obtained during all phases after each block of 4 movements, where participants reported pain expectancy and pain-related fear for each of the trajectories, of which the corresponding arches were highlighted consecutively. The questions assessing pain expectancy and pain-related fear were the following: (1) "To what extent did you expect an electrical stimulus when moving through the highlighted arch?" and (2) "How afraid were you to move through the highlighted arch?". Ratings were given using the foot switch on a numerical scale from 0 to 10 with respective labels $0=$ "not at all" and $10=$ "very much" and $0=$ "not afraid at all" and 10 = "extremely afraid."

\subsubsection{Prospective ratings}

Prospective ratings of pain expectancy and pain-related fear for each trajectory were assessed only once before the start of the AM phase and the free-choice test phase.

\subsection{Data analysis overview}

First, descriptive statistics of the sample and questionnaire scores were computed. Second, we tested whether the experimental and control group participants successfully acquired pain-related fear and avoidance behaviour during the avoidance acquisition phase (ACQ). We performed a series of $2 \times$ $3 \times 6$ group (experimental, control) $\times$ trajectory $(\mathrm{T} 1, \mathrm{~T} 2$, and $\mathrm{T} 3$ ) $\times$ block (ACQ1-6) repeated-measures analyses of variance (RM ANOVAs) on pain expectancy and pain-related fear ratings. In addition, planned comparisons for the different trajectories were performed to test acquisition of pain expectancy and pain-related fear for T1 > T3 in both groups. We also performed planned comparisons on the behavioural data during the avoidance acquisition phase to check whether experimental and control group participants learned to avoid the painful stimulus by choosing trajectory T3.

In the AM phase, we tested our first hypothesis, whether acquired avoidance behaviour in the presence of a novel movement (T2) provokes pain expectancy and pain-related fear towards that movement. We performed $2 \times 3 \times 3$ group (experimental, control) $\times$ trajectory $(\mathrm{T} 1, \mathrm{~T} 2$, and $\mathrm{T} 3) \times$ block (AM1-3) RM ANOVAs on the retrospective pain expectancy and pain-related fear ratings. With planned comparisons, we assessed whether the pain expectancy and pain-related fear ratings of $\mathrm{T} 2$ for the experimental group were higher compared with the control group at the start and end of the avoidance phase, ie, after completion of block 1 and block 3 , respectively.

To test our second hypothesis, whether elevated pain expectancy and pain-related fear for the novel movement (T2) are preserved for the experimental group during the free-choice test (TEST) phase, we performed equivalence tests, ${ }^{14}$ based on the retrospective ratings, between the last block of the AM phase and the first block of the free-choice test phase. Furthermore, we performed $2 \times 3 \times 3$ group (experimental, control) $\times$ trajectory (T1, T2, and T3) $\times$ block (TEST1-3) RM ANOVAs on pain expectancy and pain-related fear. Planned contrasts assessed whether the pain expectancy and pain-related fear ratings of T2 were higher than T3 for the experimental group and the control group during the free-choice test phase.

To test our third hypothesis, whether the experimental group participants showed proportionally more avoidance behaviour (T3) during the free-choice test phase than the control group participants, ie, persistence in avoidance behaviour, we used the chi-square $\left(\chi^{2}\right)$ test statistic on the proportion of the selection of T3 during the free-choice test.

To test our fourth hypothesis, whether persistent avoiders (during the AM phase) from the experimental group reported higher pain expectancy and pain-related fear during the freechoice test phase, we performed linear regression analyses to establish the relationship between the frequency of avoiding (selection of movement T3 during the avoidance phase) and the reported pain expectancy and pain-related fear. These analyses did show the pain expectancy and pain-related fear to be somewhat dependent on the frequency of avoiding, but the explained variance $\left(r^{2}\right)$ was rather low, and we observed bimodal data, ie, 1 group that selected T3 $\leq 6$ times of 12 trials (ie, $\leq 50 \%$ of avoidance) and 1 group that selected T3 $>6$ times of 12 trials in the avoidance phase (ie, $>50 \%$ of avoidance). As a result, we then decided to divide the experimental group in "less frequent avoiders" ( $n=14)$ and "more frequent avoiders" ( $n=36)$. Subsequently, we compared the prospective and retrospective pain expectancy and pain-related fear means of both groups with an unpaired 2 -sample $t$ test, when the variances were equal between both groups and a Welch unpaired two-sample $t$ test when the variances between groups were unequal. Please note the selection of high and less frequent avoiders was post hoc and data-driven. Table S-1 (supplementary material, available at http://links.Iww.com/PAIN/B178) includes the descriptive statistics and unpaired 2-sample $t$ tests for the questionnaires scores for the less frequent avoiders and the more frequent avoiders in the experimental group.

For each significant RM ANOVA effect, $\eta_{g}^{2}$ is reported. $\eta_{g}^{2}$ is the recommended effect size statistic for repeated measures designs. ${ }^{1}$ In case of violation of sphericity, Greenhouse-Geisser corrections were applied by correcting the degrees of freedom. All statistical tests were considered significant at $P<0.05$. Holm-Bonferroni corrections were applied to correct for multiple comparison testing. Statistical analyses for all dependent measures were run with R software (RStudio, version 1.0.153).

\section{Results}

\subsection{Descriptive statistics of the sample and questionnaires}

There was no difference in the physical intensity of the painful stimulus chosen by the experimental group $(24.94 \pm 12.17 \mathrm{~mA})$ and the control group $(22.54 \pm 12.37 \mathrm{~mA}), t(98)=0.99, P=$ 0.33 . Descriptive statistics and questionnaire scores per group are given in Table 1. The unpaired two-sample $t$ test revealed that groups did not differ in their questionnaire scores regarding fear of pain, trait anxiety, intolerance of uncertainty, and neuroticism. 
Table 1

Descriptive statistics and unpaired 2-sample $t$ tests for the questionnaire scores for the experimental group $(n=50)$ and the control group $(n=50)$.

\begin{tabular}{|c|c|c|c|c|}
\hline Total $(\mathrm{N}=100)$ & Experimental group (M [SD]) & Control group (M [SD]) & $t(98)$ & $P$ \\
\hline Age & $21.34(8.45)$ & $22.64(8.56)$ & 0.76 & 0.45 \\
\hline Pain stimulus (in mA) & $24.94(12.17)$ & $22.54(12.37)$ & 0.99 & 0.33 \\
\hline FPQ—total & $74.9(14.09)$ & $75.04(15.65)$ & -0.05 & 0.96 \\
\hline STAl-T-total & $39.66(9.84)$ & $39.42(11.05)$ & 0.11 & 0.91 \\
\hline IUS & $30.90(7.40)$ & $31.42(7.73)$ & -0.34 & 0.73 \\
\hline$E P Q-N$ & $9.58(4.98)$ & $9.02(5.52)$ & 0.53 & 0.60 \\
\hline
\end{tabular}

EPQ-N, Neuroticism scale of the Eysenck Personality Questionnaire; FPQ, Fear of Pain Questionnaire; IUS, Intolerance of Uncertainty Scale; STAI-T, Trait version of the State-Trait Anxiety Inventory.

\subsection{Manipulation checks}

\subsubsection{Acquisition: behavioural avoidance}

As expected, participants of both groups chose T3 more often than T1 during the avoidance acquisition phase: T1 $\exp$ Vs T3 $3_{\text {exp }}$ $\chi^{2}(1)=745.94, P<0.0001 ; T_{\text {ctrl }}$ vs T3 ${ }_{\text {ctrl }}: \chi^{2}(1)=582.14, P<$ 0.0001 . Please also see Figure $3 \mathrm{~A}$.

\subsubsection{Acquisition: pain expectancy and pain-related fear}

Figures 4 and 5 show the acquisition of pain expectancy and pain-related fear, respectively. The analysis of pain expectancy during avoidance acquisition revealed a significant main effect of trajectory, $\mathrm{F}(2,196)=484.61, P<0.001, \eta_{g}^{2}=0.71$, and $\mathrm{a}$ significant block $\times$ trajectory interaction, $F(5.86,574.53)=$ 10.35, $P<0.001, \eta_{g}^{2}=0.02$. As expected, there was neither a main effect of group, $\mathrm{F}(1,98)=0.69, P=0.41$, nor a significant three-way group $\times$ block $\times$ trajectory interaction, $F(10,980)=$ $0.57, P=0.84$. Planned contrasts confirmed that both groups expected the painful stimulus more to occur during $\mathrm{T} 1 \mathrm{compared}$ with T3 at the end of avoidance acquisition (experimental group: $\mathrm{F}(1,98)=538.3, P<0.0001$; control group: $\mathrm{F}(1,98)=359.4, P$ $<0.0001)$.

The analysis of pain-related fear during the avoidance acquisition phase revealed similar results: a significant main effect of trajectory, $\mathrm{F}(2,196)=273.75, P<0.001, \eta_{g}^{2}=0.55$, and a significant block $\times$ trajectory interaction $F(4.25,416.80)=$ 13.08, $P<0.001, \eta_{g}^{2}=0.02$. Again, as expected, there was neither a main effect of group, $\mathrm{F}(1,98)=0.25, P=0.62$, nor a significant three-way group $\times$ block $\times$ trajectory interaction, $F(10$, $980)=0.44, P=0.92$. Planned contrasts confirmed that both groups were more afraid when performing T1 compared with T3 at the end of avoidance acquisition (experimental group: $F(1,98)$ $=271, P<0.0001$; control group: $\mathrm{F}(1,98)=191.4, P<0.0001)$.

In conclusion, the manipulation checks confirmed that participants in both groups learned to expect a painful stimulus during the T1 movement and feared to perform this movement by the end of the avoidance acquisition phase. Both groups learned to effectively avoid the painful stimulus by performing the longest trajectory T3.

\subsection{Hypothesis 1: Acquired avoidance behaviour in the presence of a novel movement (T2) provokes pain expectancy and pain-related fear towards that movement}

\subsubsection{Pain expectancy}

Figure 4 shows the pain expectancy ratings for both groups. The analysis on pain expectancy during the AM phase revealed significant main effects of group, $\mathrm{F}(1,98)=18.99, P<0.0001, \eta_{g}^{2}$ $=0.06$, trajectory, $\mathrm{F}(1.69,165.66)=85.27, P<0.0001, \eta_{g}^{2}=$ 0.33 , and block, $F(1.61,157.43)=48.06, P<0.0001, \eta_{g}^{2}=0.01$. Furthermore, the group $\times$ block interaction reached significance, $F(1.61,157.43)=6.24, P=0.005, \eta_{g}^{2}=0.002$, as well as the group $\times$ trajectory interaction, $F(1.69,165.66)=9.79, P<$ $0.001, \eta_{g}^{2}=0.05$, and the trajectory $\times$ block interaction, $F(1.92$, $188.14)=10.46, P<0.001, \eta_{g}^{2}=0.008$. The crucial comparison of the pain expectancy ratings for the novel movement (T2) between the experimental group and the control group reached significance at both the start of the AM phase: T2 exp Vs T2 $2_{\text {ctrl }} \mathrm{F}(1$, $98)=17.84, P<0.001$ and the end of the AM phase: T2 exp Vs $\mathrm{T} 2_{\text {ctrl }} \mathrm{F}(1,98)=40.01, P<0.0001$. In sum, participants of the experimental group expected a painful stimulus more to occur with the novel movement (T2) compared with the control group.

\subsubsection{Pain-related fear}

In Figure 5, the pain-related fear ratings for both groups are displayed. The analysis of pain-related fear during the AM phase showed similar results as the pain expectancy analysis. Following main effects were significant: group, $F(1,98)=12.18, P<0.001, \eta_{g}^{2}=0.05$, trajectory, $\mathrm{F}(1.85,180.96)=88.48, P<0.0001, \eta_{g}^{2}=0.32$, and block, $\mathrm{F}(1.58$, $154.39)=38.99, P<0.0001, \eta_{g}^{2}=0.01$. The following interactions were significant as well: group $\times$ block interaction, $F(1.58,154.39)=$ 7.59, $P<0.01, \eta_{g}^{2}=0.003$, group $\times$ trajectory interaction, $\mathrm{F}(1.85$, 180.96) $=3.50, P<0.05, \eta_{g}^{2}=0.02$, and trajectory $\times$ block interaction, $\mathrm{F}(2.59,253.97)=10.46, P<0.0001, \eta_{g}^{2}=0.006$. The planned comparisons between the experimental group and the control group were significant at the start of the avoidance phase: $\mathrm{T}_{2}$ exp vs T2 $2_{\text {ctrl }} \mathrm{F}(1,98)=4.56, P=0.035$ and at the end of the avoidance phase: $\mathrm{T} 2_{\text {exp }}$ vs T2 $\operatorname{ctrl} F(1,98)=23.73, P<0.0001$. These results indicate that participants of the experimental group were more afraid to perform T2 compared with the control group.

\subsection{Hypothesis 2: preservation of pain expectancy and pain- related fear during the free-choice test phase}

\subsubsection{Pain expectancy}

The analysis on pain expectancy during the free-choice test phase revealed significant main effects of trajectory, $F(1.82,178.40)=$ 364.77, $P<0.0001, \eta_{g}^{2}=0.71$, and block, $F(1.42,138.84)=10.39$, $P<0.001, \eta_{g}^{2}=0.003$. The main effect of group failed to reach significance, $\mathrm{F}(1,98)=3.31, P=0.07, \eta_{g}^{2}=0.009$. The group $\times$ trajectory interaction, $F(1.82,178.40)=9.38, P<0.001, \eta_{g}^{2}=0.06$, and the trajectory $\times$ block interaction, $F(2.62,256.96)=18.59, P<$ $0.001, \eta_{g}^{2}=0.01$, were significant. To test whether pain expectancy for the T2 movement was maintained for the experimental group, we 


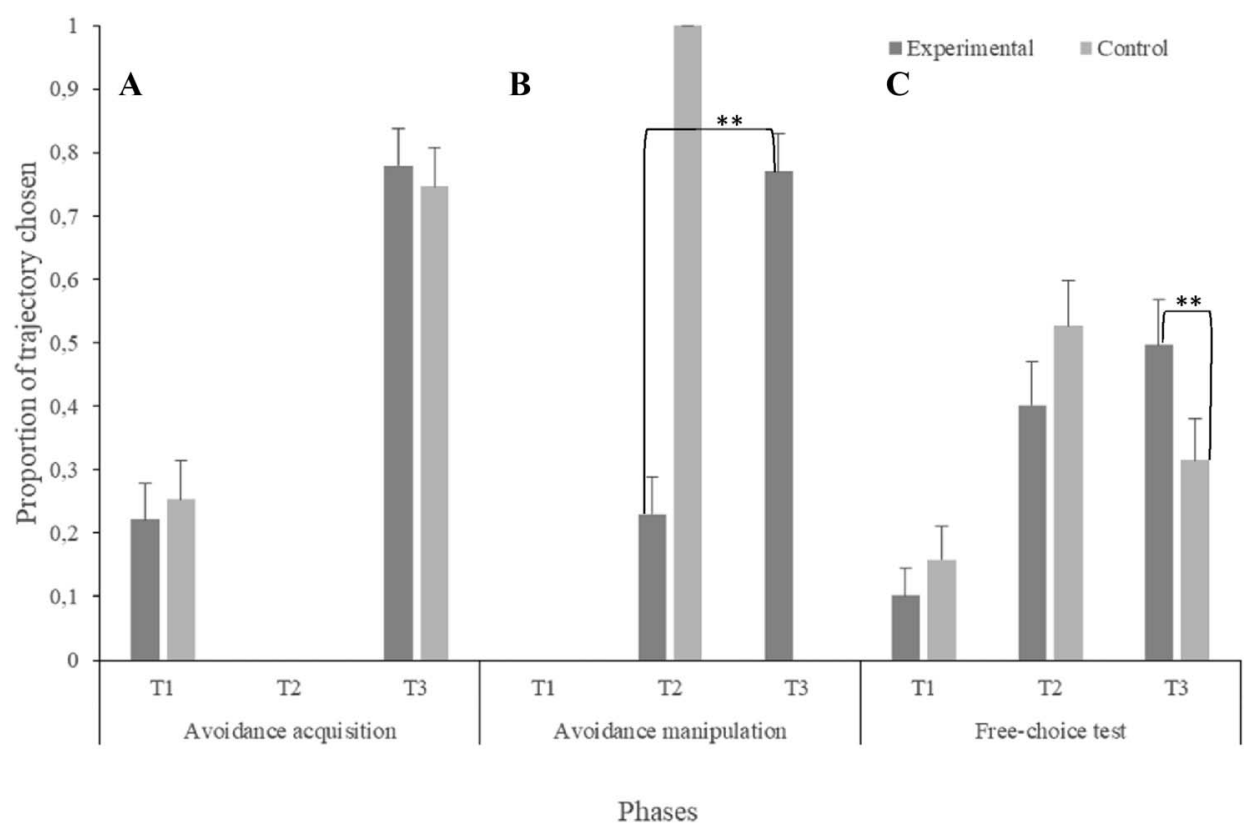

Figure 3. Behavioural data on avoidance with standard error bars for all trajectories ( $\mathrm{T} 1$, $\mathrm{T} 2$, and $\mathrm{T} 3$ ) during the (A) avoidance acquisition, (B) avoidance manipulation, and (C) free-choice test phase for the experimental group and the control group, ${ }^{\star *} P<0.01$.

performed an equivalence test. The equivalence test revealed that the pain expectancy between the last block of the avoidance phase and first block of the free-choice test phase was not statistically equivalent $t(49)=4.26, P=0.99$. In other words, the elevated pain expectancy ratings were not maintained at the same level. However, the experimental group still reported higher pain expectancy for T2 during the free-choice test phase compared with $T 3, F(1,48)=$ 16.39, $P<001$, while for the control group, we did not observe this difference in pain expectancy between T2 and T3, $\mathrm{F}(1,48)=0.99, P$ $=0.33$. In sum, experimental group participants did not report the same level of pain expectancy for the novel movement (T2) during test compared with during the AM phase; however, they still expected the pain more than for trajectory T3.

\subsubsection{Pain-related fear}

The analysis on pain-related fear during the free-choice test phase revealed a significant main effect of trajectory, $F(2,196)=$ 235.29, $P<0.0001, \eta_{g}^{2}=0.55$, and block, $\mathrm{F}(1.56,152.99)=$ 18.86, $P<0.0001, \eta_{g}^{2}=0.006$. Furthermore, the group $\times$ trajectory interaction, $F(2,196)=7.28, P<0.001, \eta_{g}^{2}=0.04$, and the trajectory $\times$ block interaction, $\mathrm{F}(2.83,277.09)=11.85, P$ $<0.0001, \eta_{g}^{2}=0.007$, reached significance. To test our hypothesis, we compared the pain-related fear ratings of the T2 movement during the last block of the avoidance phase and the first block of the free-choice test phase for the experimental group and found that the pain-related fear reported by the experimental group participants was also not statistically equivalent $t(49)=$ 3.99, $P=0.99$. However, experimental group participants were more afraid to perform T2 compared with T3 during the freechoice test phase, $\mathrm{F}(1,48)=19.27, P<0.001$, while the control group participants did not report such difference, $F(1,48)=1.97$, $P=0.17$. In sum, experimental group participants did not maintain the same level of pain-related fear to perform T2 during the free-choice test phase. However, they did report higher painrelated fear for T2 compared with T3.

\subsection{Hypothesis 3: persistence in avoidance behaviour during the free-choice test phase}

To test whether the experimental group avoided more compared with the control group during the free-choice test phase, we compared the proportion of T3 choices between both groups. Proportion T3 choices during the free-choice test phase for the experimental group were 0.50 and for the control group were $0.32, \chi^{2}(1)=40.31, P<0.0001$. In other words, participants of the experimental group avoided on $50 \%$ of the trials during the free-choice test phase, and control group participants only avoided approximately on one-third of the trials (32\%) during the free-choice test phase (see Fig. $\mathbf{3 C}$ for the choice data in the freechoice test phase).

\subsection{Hypothesis 4: More frequent avoiders report higher pain expectancy and pain-related fear than less frequent avoiders}

To test the hypothesis that experimental group participants, who avoided more during the avoidance phase, would also report higher pain expectancy and pain-related fear during the free-choice test phase, we divided the sample post hoc into less frequent avoiders $(n=14)$ and more frequent avoiders $(n=36)$.

\subsubsection{Pain expectancy}

The results of the pain expectancy ratings during the free-choice test phase for the less frequent avoiders and more frequent avoiders of the experimental group are shown in Figure 6. In all cases, the more frequent avoiders group showed higher levels of pain expectancy towards the novel movement T2 compared with the less frequent avoiders: before the free-choice test phase, $t(48)=4.12, P<0.001$; block $1, t(47.92)=5.56, P<$ 0.0001 ; block $2, t(41.90)=5.63, P<0.0001$; and block $3, t(48)$ $=2.12, P=0.039$. 

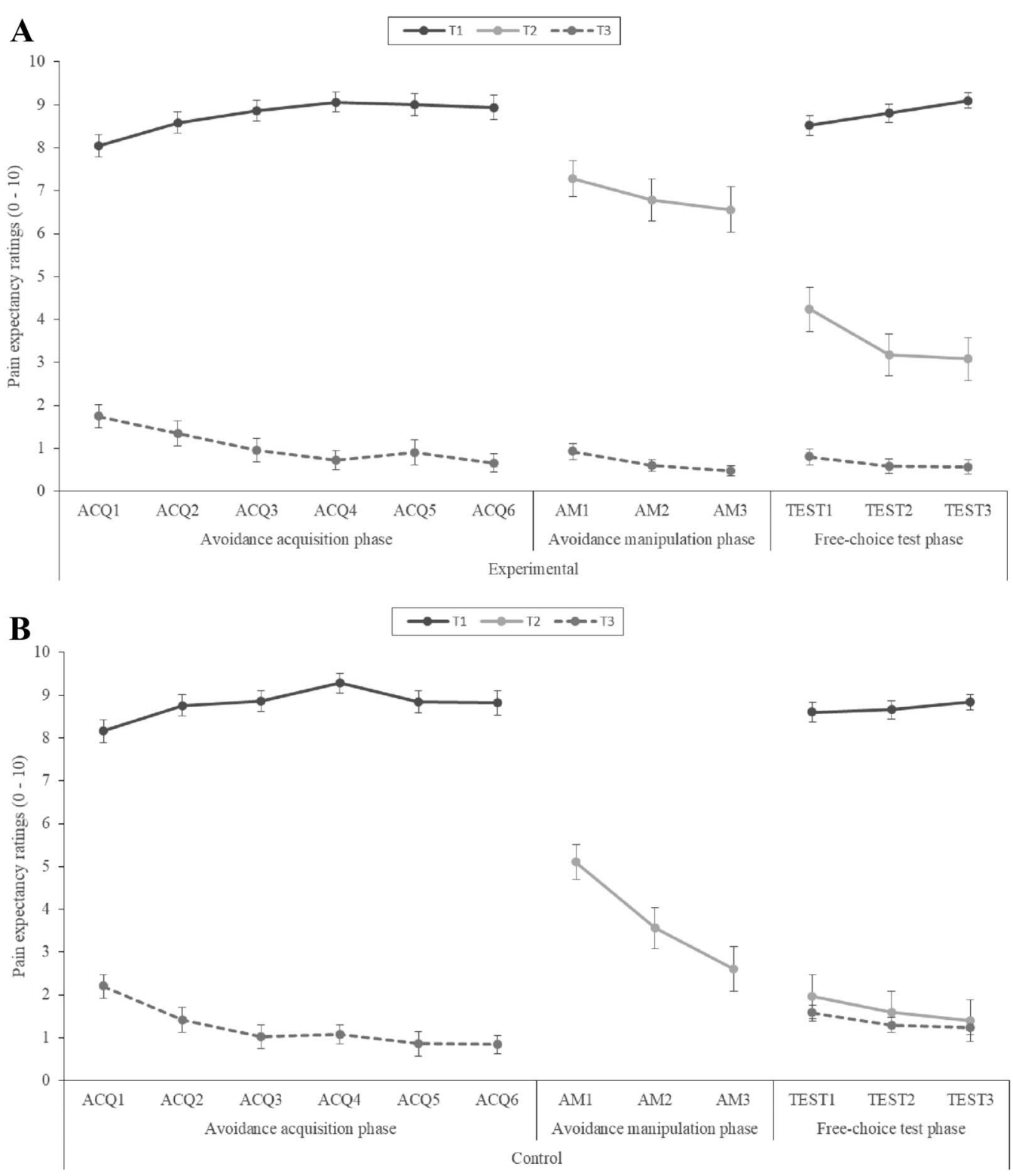

Figure 4. Pain expectancy ratings with standard error bars for all trajectories ( $\mathrm{T} 1, \mathrm{~T} 2$, and $\mathrm{T} 3)$ during the avoidance acquisition, avoidance manipulation, and freechoice test phase for the experimental group (A) and the control group (B).

\subsubsection{Pain-related fear}

The results of the pain-related fear ratings during the free-choice test phase for the less frequent avoiders and more frequent avoiders of the experimental group were similar to those of the pain expectancy ratings and are shown in Figure 7. In all cases, the more frequent avoiders group showed higher levels of painrelated fear towards the novel movement compared with the less frequent avoiders: before the free-choice test phase, $t(48)=3.65$, $P<0.001$; block 1, $t(44.55)=4.38, P<0.0001$; block $2, t(48)=$ 2.03, $P=0.04$; and block $3, t(48)=2.11, P=0.04$.

\section{Discussion}

This study addressed 2 main questions: (1) whether avoidance behaviour performed in the context of a novel, ambiguous movement increases threat and pain-related fear and (2) whether avoidance behaviour persists when given the choice between performing the known movement to avoid a painful stimulus or an alternative, novel movement. We measured pain expectancies and pain-related fear for 3 different movements. The experimental group and the control group learned to avoid a pain-associated movement (T1) by performing a longer, nonpainful movement (T3). These findings replicated the results of previous studies of avoidance acquisition, using a similar paradigm, albeit in the absence of associated cost when performing the avoidance movement. 20,32

In line with our first hypothesis, acquiring avoidance behaviour in the presence of a novel, ambiguous movement (T2) provoked higher pain expectancy and pain-related fear ratings for that movement, thereby extending the findings of Lovibond et al. $^{16}$ In Lovibond's experiment, the experimental group was given the opportunity to perform an avoidance response during extinction, whereas the control group was not given this opportunity. In that study, differences were observed in return of fear between both groups when the extinguished, previously fearful stimulus was tested without an avoidance response being available. Apparently, for the experimental group, the opportunity to perform an 


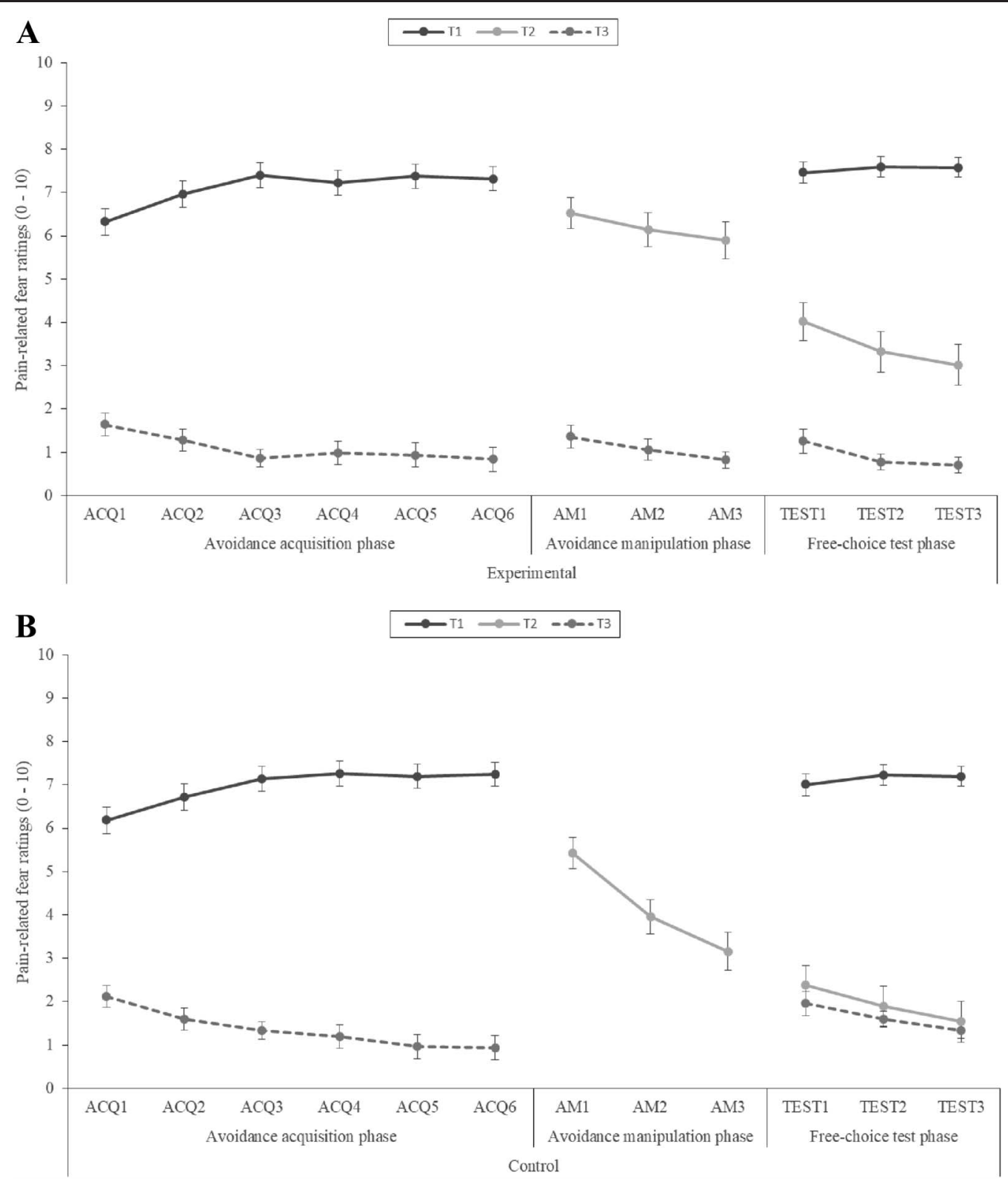

Figure 5. Pain-related fear ratings with standard error bars for all trajectories ( $\mathrm{T} 1, \mathrm{~T} 2$, and $\mathrm{T} 3)$ during the avoidance acquisition, avoidance manipulation, and freechoice test phase for the experimental group (A) and the control group (B).

avoidance response had prevented fear extinction and maintained threat expectations for the fear-evoking stimulus. As a result, only the control group showed extinction. Potential explanations for the observed role of acquired avoidance behaviour on the transfer of pain expectancy and pain-related fear could be the following. First, the use of "behaviour as information," whereby participants used their own avoidance behaviour to infer threat, ie, ex-consequentia reasoning. ${ }^{10,28}$ In other words, they assumed that the novel movement had to be unsafe/painful, just because they were avoiding, although this was not necessarily a correct conclusion. Second, the mere availability to avoid may cause increased threat expectancies. After acquiring an avoidance response towards a painful movement (T1), the avoidance response itself may induce transfer of threat expectancies and pain-related fear towards a similar, novel movement (T2). The availability of the acquired avoidance response may function as a contextual cue, indicating the potential threat of $\mathrm{T} 2$ that needed to be prevented by performing an avoidance response. ${ }^{7}$ Third, earlier findings suggested that risk perception is influenced by intuitive processes and is not only the result of rational analysis. ${ }^{27}$ This intuitive process may lead to misperceptions of the threat of the ambiguous novel movement because the acquired avoidance behaviour served as a reminder of pain expectancy and painrelated fear.

Our results did not fully support our second hypothesis where we anticipated elevated levels of pain expectancy and painrelated fear for the novel movement (T2) to be maintained from avoidance to the free-choice test phase. Experimental group participants reported lower levels of pain expectancy and painrelated fear for the novel movement T2 in the free-choice test phase compared with the reported levels for T2 in the AM phase. However, experimental group participants reported higher pain expectancy and pain-related fear for movement T2 compared with the avoidance movement (T3) in the free-choice test phase, while participants of the control group did not differentiate in their 


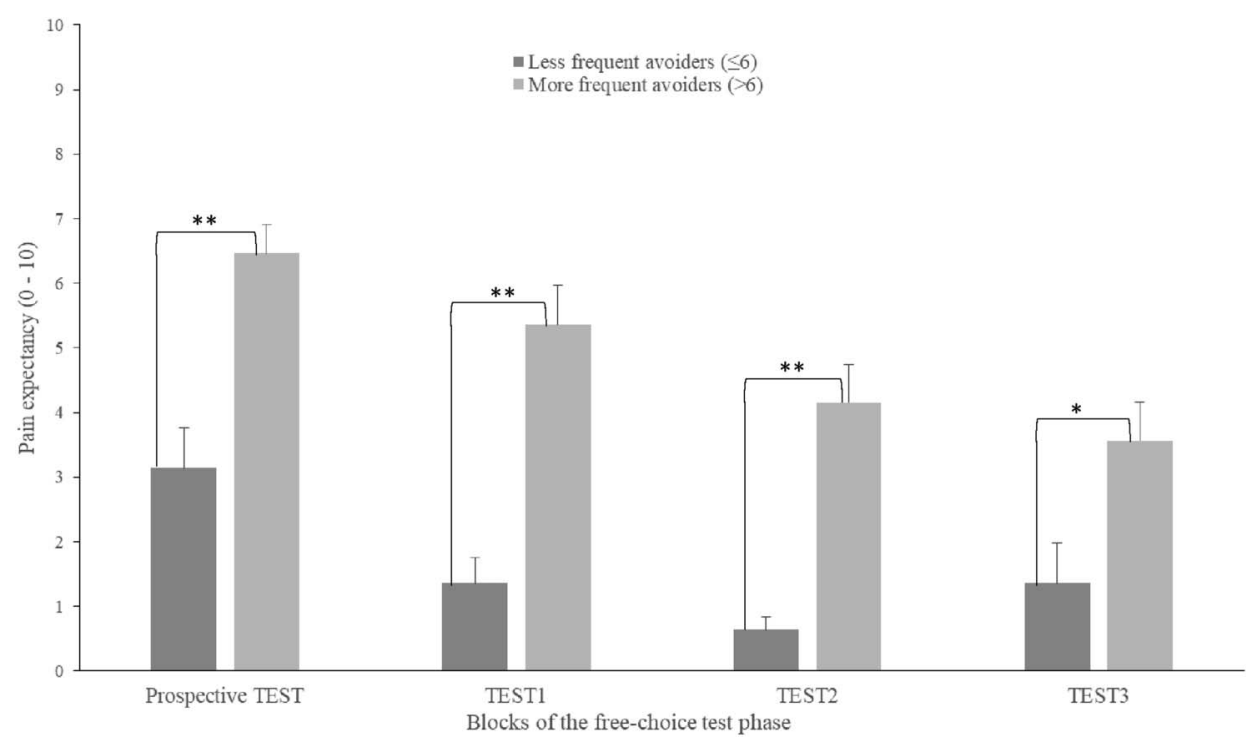

Figure 6. Pain expectancy ratings towards the novel movement $\mathrm{T} 2$ for less frequent avoiders and more frequent avoiders of the experimental group during the freechoice test phase, ${ }^{*} P<0.05$; ${ }^{\star \star} P<0.01$.

pain expectancy and pain-related fear between these movements. Earlier research ${ }^{31,32}$ had suggested a bidirectional relationship between avoidance and pain-related fear. Avoidance behaviour itself may lead participants to infer danger for a newly introduced movement, assuming this movement may be dangerous as well, merely because it could be avoided. Similar findings have been reported in research about the persistence of anxiety disorders, where safety behaviours have led to excessive and persistent fear of objectively safe stimuli. ${ }^{24}$ This could be caused by the misattribution of safety as a result of performing a safety/avoidance behaviour, thereby preserving excessive danger beliefs. ${ }^{4,23,26}$

The results of our current study supported our third hypothesis: Experimental group participants were more persistent in engaging in previously acquired avoidance behaviour (T3) compared with control group participants. Although experimental group participants explored the novel movement (T2) more during the free-choice test phase than during the AM phase, they mostly performed the previously acquired avoidance response (T3), thereby preventing disconfirmation of potential threat associated with the novel movement. This finding is in line with earlier research by van Vliet et al., ${ }^{32}$ where persistence of avoidance was observed using a similar movement-related paradigm. Taken together, these observations regarding persisting in avoidance behaviour are important for our understanding of the mechanisms involved in the development of chronic pain. Also, control group participants still avoided in approximately $30 \%$ of the trials in the free-choice test phase, although the pain expectancy and pain-related fear for movement T2 had been extinguished for the control group in the AM phase. In other words, there was no logical reason for the control group to avoid the safe/nonpainful movement T2. This finding is in line with the results reported by

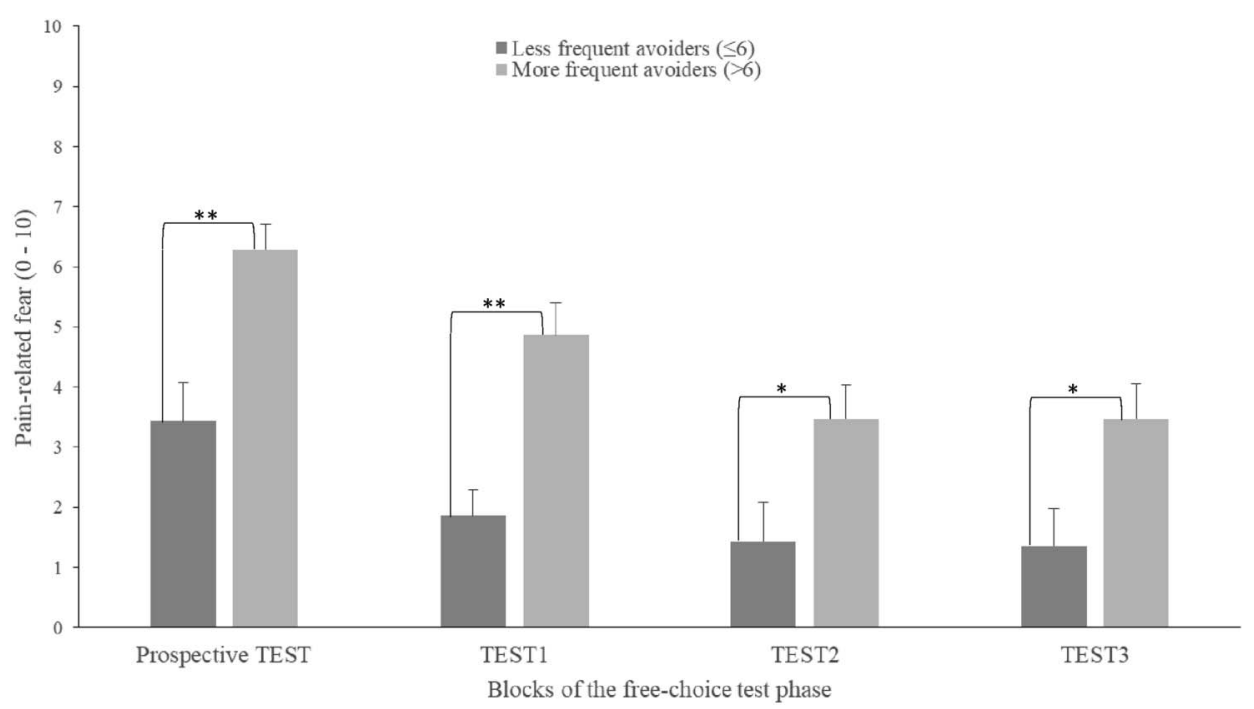

Figure 7. Pain-related fear ratings towards the novel movement $T 2$ for less frequent avoiders and more frequent avoiders of the experimental group during the freechoice test phase, ${ }^{*} P<0.05 ;{ }^{* \star} P<0.01$. 
Vervliet and Indekeu, ${ }^{33}$ who found that avoidance behaviour can reoccur after successful fear extinction, when the avoidance response became available again. Also, the return of the availability to avoid may have acted as a negative occasion setter as described by De Houwer et al. 5,6

Regarding our fourth hypothesis, we found that more frequent avoiders reported higher pain expectancies and pain-related fear during the free-choice test phase. This result suggested that not only acquired avoidance behaviour by itself can increase pain expectancy and pain-related fear but also the frequency of performing the avoidance behaviour has an effect on those measures. These findings are supported by the idea of ex-consequentia reasoning $^{10,28}$; based on their own consequent avoidance behaviour, participants drew invalid conclusions about the outcome associated with T2, and therefore reasoned, "I am avoiding, so it must be dangerous and therefore I am afraid of the movement."

One of the strengths of this study is the successful operationalisation of movement-related avoidance, further validating a paradigm that allowed participants to perform avoidance during an ecologically valid arm-reaching task. ${ }^{3,13,20}$ Rather than operationalising avoidance by, eg, simply pressing a button upon a cue, here, the participants learned to avoid painful stimuli by performing different robotic arm movements. Other strengths are the introduction of a novel movement, after avoidance acquisition, and the design of the free-choice test phase. Avoidance behaviour can be considered as a decision-making process in our paradigm (ie, choice), taking into account the benefits (averting a painful stimulus) as well as the expected costs of avoidance. ${ }^{36}$ An innovative aspect of our study was to investigate the effects of avoidance behaviour in the context of a novel, ambiguous movement, on threat expectancies and fear towards that movement. During the free-choice test phase, we collected data on self-reported pain expectancy and pain-related fear across multiple blocks of trials, allowing us to obtain a trend of the self-reported measures across this phase, compared with other studies where often the test phase consisted of only 1 trial. ${ }^{7,16}$ One of the limitations of the study is the use of a non-sexbalanced sample for our experiment, which consisted for $80 \%$ of female participants. Since females may have enhanced fear acquisition ${ }^{17,23}$ and pain sensitivity during fear conditioning, ${ }^{21}$ future research may benefit from obtaining more sex-balanced samples. Another limitation of the study is the single-trial reinforcement of T2 to induce the avoidance behaviour for T2 because earlier pilot testing had shown experimental group participants hardly avoided T2 in the absence of this single-trial reinforcement. This means that transfer of pain-related fear and pain expectancy was not only determined by the acquired avoidance but also by the single-trial reinforcement. This could have created some ambiguity because for a number of participants, this might have been sufficient evidence that T2 is a dangerous movement, and they refrained from checking further in subsequent trials. ${ }^{2}$ Although avoidance may not have been affected, a potential confound in this paradigm is the placement of T2 close to T1 (generalisation of the threat based on perceptual/proprioceptive similarity with $\mathrm{T} 1$ ) and to the left of T3 (rule-based generalisation). ${ }^{11}$ Placing T2 to the right of T3 may have been better to control for the potential generalisation. Another limitation is the absence of an additional phase where none of the movements were reinforced. Adding such a phase would enable studying extinction of avoidance behaviour for either the experimental group, the control group, or both groups.

To conclude, the results indicated that avoiding in the context of a novel, ambiguous movement provoked pain expectancy and pain-related fear towards that movement, even in the absence of confirmation of the actual threat level of the movement. Also we observed persistent avoidance in the presence of that novel movement, which can be considered maladaptive and disproportionate to the threat and may have prevented disconfirmation of threat appraisals. The results from this study support the bidirectionality hypothesis between avoidance behaviour and fear, whereby fear leads to avoidance and, in turn, avoidance further increases fear. These findings can potentially help to further our understanding of how persisting in avoidance behaviour may lead to the development and maintenance of irrational fears and threat appraisals.

\section{Conflict of interest statement}

The authors have no conflicts of interest to declare.

\section{Acknowledgments}

This research was supported by the "Asthenes" long-term structural funding Methusalem grant by the Flemish Government, Belgium (METH/15/011). Ann Meulders is a postdoctoral researcher of the Research Foundation Flanders (FWO-Vlaanderen), Belgium (grant ID: 12E3717N), and is supported by a Vidi grant from the Netherlands Organization for Scientific Research (NWO), the Netherlands (grant ID 452-17-002).

\section{Appendix A. Supplemental digital content}

Supplemental digital content associated with this article can be found online at http://links.Iww.com/PAIN/B178.

\section{Article history:}

Received 11 June 2020

Received in revised form 6 September 2020

Accepted 9 September 2020

Available online 16 September 2020

\section{References}

[1] Bakeman R. Recommended effect size statistics for repeated measures designs. Behav Res Methods 2005;37:379-84.

[2] Bensi L, Giusberti F. Trait anxiety and reasoning under uncertainty. Pers Indiv Differ 2007;43:827-38.

[3] Claes N, Vlaeyen JW, Crombez G. The impact of Pavlovian cues on pain avoidance: a behavioral study. Learn Motiv 2016;56:73-83.

[4] Clark DM. Anxiety disorders: why they persist and how to treat them. Behav Res Ther 1999;37:S5-S27.

[5] Declercq M, De Houwer J. Evidence for the interchangeability of an avoidance behavior and a negative occasion setter. Learn Behav 2008; 36:290-300.

[6] De Houwer J, Crombez G, Baeyens F. Avoidance behavior can function as a negative occasion setter. J Exp Psychol 2005;31:101.

[7] Engelhard IM, van Uijen SL, van Seters N, Velu N. The effects of safety behaviour directed towards a safety cue on perceptions of threat. Behav Ther 2015;46:604-10.

[8] Festinger L. A theory of cognitive dissonance. Stanford, CA: Stanford University Press, 1957.

[9] Forrest S, Lewis CA, Shevlin M. Examining the factor structure and differential functioning of the Eysenck Personality Questionnaire RevisedAbbreviated. Pers Indiv Differ 2000;29:579-88.

[10] Gangemi A, Mancini F, van den Hout M. Behavior as information: "If I avoid, then there must be a danger". J Behav Ther Exp Psychiatry 2012;43:1032-8.

[11] Glogan E, Gatzounis R, Meulders M, Meulders A. Generalization of instrumentally acquired pain-related avoidance to novel but similar movements using a robotic arm-reaching paradigm. Behav Res Ther 2020;124:103525.

[12] Helsen K, Van den Bussche E, Vlaeyen JW, Goubert L. Confirmatory factor analysis of the Dutch Intolerance of Uncertainty Scale: comparison of the full and short version. J Behav Ther Exp Psychiatry 2013;44:21-9. 
[13] Janssens T, Meulders A, Cuyvers B, Colloca L, Vlaeyen JW. Placebo and nocebo effects and operant pain-related avoidance learning. Pain Rep 2019;4:e748.

[14] Lakens D. Equivalence tests: a practical primer for $t$ tests, correlations, and meta-analyses. Soc Psychol Personal Sci 2017;8:355-62.

[15] Lethem J, Slade PD, Troup JD, Bentley G. Outline of a FearAvoidance Model of exaggerated pain perception-I. Behav Res Ther 1983;21:401-8.

[16] Lovibond PF, Mitchell CJ, Minard E, Brady A, Menzies RG. Safety behaviours preserve threat beliefs: protection from extinction of human fear conditioning by an avoidance response. Behav Res Ther 2009;47: 716-20.

[17] McClure EB, Monk CS, Nelson EE, Zarahn E, Leibenluft E, Bilder RM, Charney DS, Ernst M, Pine DS. A developmental examination of gender differences in brain engagement during evaluation of threat. Biol Psychiatry 2004;55:1047-55.

[18] McNeil DW, Rainwater AJ. Development of the fear of pain questionnaireIII. J Behav Med 1998;21:389-410.

[19] Meulders A. Fear in the context of pain: lessons learned from 100 years of fear conditioning research. Behav Res Ther 2020;131:103635.

[20] Meulders A, Franssen M, Fonteyne R, Vlaeyen JW. Acquisition and extinction of operant pain-related avoidance behavior using a 3 degreesof-freedom robotic arm. PAIN 2016;157:1094-104.

[21] Meulders A, Vansteenwegen D, Vlaeyen JW. Women, but not men, report increasingly more pain during repeated (un)predictable painful electrocutaneous stimulation: evidence for mediation by fear of pain. PAIN 2012;153:1030-41.

[22] Pittig A. Incentive-based extinction of safety behaviors: positive outcomes competing with aversive outcomes trigger fear-opposite action to prevent protection from fear extinction. Behav Res Ther 2019;121:103463.

[23] Pittig A, Wong AH, Glück VM, Boschet JM. Avoidance and its bidirectional relationship with conditioned fear: mechanisms, moderators, and clinical implications. Behav Res Ther 2020:103550.

[24] Rachman S, Radomsky AS, Shafran R. Safety behaviour: a reconsideration. Behav Res Ther 2008;46:163-73.
[25] Roelofs J, Peters ML, Deutz J, Spijker C, Vlaeyen JW. The Fear of Pain Questionnaire (FPQ): further psychometric examination in a non-clinical sample. PAIN 2005;116:339-46.

[26] Salkovskis PM. The importance of behaviour in the maintenance of anxiety and panic: a cognitive account. Behav Cogn Psychotherapy 1991;19:6-19.

[27] Slovic P, Peters E. Risk perception and affect. Curr Dir Psychol Sci 2006; 15:322-5.

[28] van den Hout M, Gangemi A, Mancini F, Engelhard IM, Rijkeboer MM, Van Dams M, Klugkist I. Behavior as information about threat in anxiety disorders: a comparison of patients with anxiety disorders and nonanxious controls. J Behav Ther Exp Psychiatry 2014;45:489-95.

[29] Van der Ploeg HM. Validity of the Zelf-Beoordelings-Vragenlijst (A Dutch version of the Spielberger State-Trait Anxiety Inventory). Nederlands Tijdschrift Voor de Psychol en haar Grensgebieden 1980;35:243-9.

[30] van Uijen SL, Leer A, Engelhard IM. Safety behavior after extinction triggers a return of threat expectancy. Behav Ther 2018;49:450-8.

[31] van Vliet CM, Meulders A, Vancleef LM, Vlaeyen JW. The opportunity to avoid pain may paradoxically increase fear. J Pain 2018;19:1222-30.

[32] van Vliet CM, Meulders A, Vancleef LM, Meyers E, Vlaeyen JW. Changes in pain-related fear and pain when avoidance behavior is no longer effective. J Pain 2020;21:494-505.

[33] Vervliet B, Indekeu E. Low-cost avoidance behaviors are resistant to fear extinction in humans. Front Behav Neurosci 2015:9:351.

[34] Vlaeyen JWS, Crombez G. Behavioral conceptualization and treatment of chronic pain. Annu Rev Clin Psychol 2020;16:187-212.

[35] Vlaeyen JWS, Linton SJ. Fear-avoidance and its consequences in chronic musculoskeletal pain: a state of the art. PAIN 2000;85:317-32.

[36] Volders S, Boddez Y, De Peuter S, Meulders A, Vlaeyen JW. Avoidance behavior in chronic pain research: a cold case revisited. Behav Res Ther 2015;64:31-7.

[37] Volders S, Meulders A, De Peuter S, Vervliet B, Vlaeyen JW. Safety behavior can hamper the extinction of fear of movement-related pain: an experimental investigation in healthy participants. Behav Res Ther 2012; 50:735-46. 